\title{
An Analysis of Human Factors in Industrial Design Management
}

\author{
Cheng Yong, Li Fuxing \\ Xuzhou institute of technology,Xuzhou Construction Vehicles Appearance and Function Design \\ Research Center,Xuzhou 221008,China \\ Saintlyboy@163.com
}

Keywords: industrial design, design management, human factor, teamwork

\begin{abstract}
After an investigation and analysis of industrial design companies, it's found that currently the talent is still the problem in front of many companies. Wherein, the main problems are as follows: the design supervisors don't have strong ability; the relationship among designers is not harmonious; designers have difficulty communicating with clients. And such factors directly impact the successful progression of design activities. Through an analysis and summary, this paper introduced the specific measures as to how human beings can better participate in design activities, and the importance of teamwork, so as to ensure the successful progression of design activities.
\end{abstract}

\section{Introduction}

With the ever-changing technology and the fierce market competition, people's insufficient understanding and attention to industrial design have resulted in the disordered and unsystematic design. Then, how to integrate the different functional departments in the company and achieve the optimization of resources involves solving the problem--to handle well the relationship between design and management, which is design management. It's a process, in which different activities in company, including product design, environmental design, visual design, etc., are rationalized and organized. After an investigation and analysis of industrial design companies, it's found that currently the talent is still the problem in front of many companies. Wherein, the main problems are as follows: the design supervisors fail to perform their responsibility; the relationship among designers is inharmonious; designers have difficulty communicating with clients. And such factors directly impact the successful progression of design activities, and the company development ${ }^{[1]}$.

\section{Those Involved in Design Activities}

"Valuing people" is an important factor of Chinese traditional management, which includes two aspects: one is valuing the trend of public sentiment, and the other is valuing the talents. To usurp the throne, govern the country and achieve something, talent is the top priority. Therefore, our country always stresses how to select and make use of talents. In resource management, talent is the most important factor. The executors of design activity have played a decisive role in the successful progression of design activity. To make the human factor the key of design management is essential for guaranteeing the success of design. 


\subsection{Design Supervisor}

So far, the design supervisors are those either with management background or design background. So, it's really difficult for them to have a systematic grasp of both management and design knowledge. As design supervisors, they should have both high intelligent quotient and high emotional quotient. The so-called intelligence quotient refers to people's ability to learn about objective things and apply knowledge to solve practical problems. Emotional quotient requires design supervisors to have relatively strong sociability, be outgoing and pleasant; and they should not be easily sentimental. At the same time, they should be positive, active, upright and full of sympathy. And they should be able to endure the pressure from various aspects under the fierce competition condition.

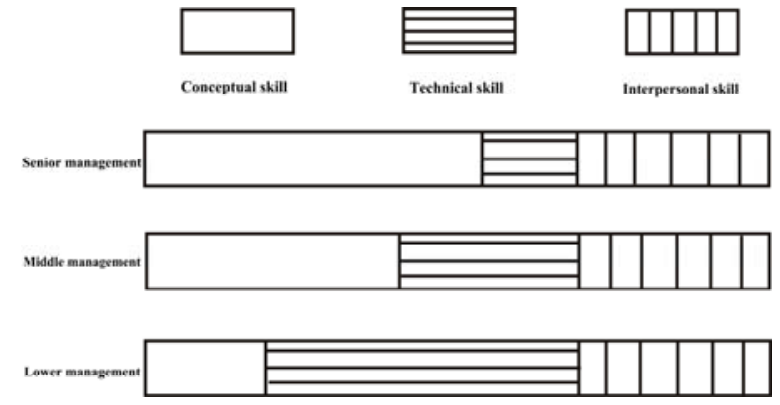

Figure 1 Skills Essential for Managers at Various Levels

\subsubsection{Design Management}

The organization structure of design management should be a top-down mode. In the decision-making department, there will be someone solely responsible for the design management. To be more exact, in the decision-making department, there will at least one person who has strong interest in design, is able to be responsible for the design work and coordinate the various design activities in the company. For example, in Korea, companies put designer at the management position. Then, through the design thinking mode, designers extend his influence to more people. At the same time, if the social system is more open-minded, it will help people reach a consensus about design and innovation. As the general helmsmen in the product development process, design managers are also the executors of design management, and they play an essential role in the whole product development process. Just as Sohrab Vossoughi, president of ZIBA Design Company, said, design managers should give full play to their guidance role, talk to not sermon the members of the design team, but they should not restrict the creativity. In addition, while cultivating the creativity inside the team, design managers should benefit the organization, help those non-design-managers learn to stimulate and develop the creativity of the group and team ${ }^{[2]}$. For example, the key of a creative thinking is to retain all judgments at the early development stage and allow all kinds of ideas and concepts. When design managers learn about the great effectiveness of this method, they will establish a mode for cultivating creativity within their own team. Therefore, design managers can generate a kind of ripple effect within the whole organization.

\subsubsection{Human Management}

The nature of human management: management activity is carried out by human beings; both the managers and subordinates are all human beings. Therefore, their ability directly impacts the management level of the organization and guarantees the effective implementation of management. So the management activity should center upon human beings and regard them as the most important resources. The core of management is to manage the people. China is a country of ceremonies and also a country of relationships. In most cases, the worldly wisdom prevails over rules and laws. And good deed is not duly rewarded nor bad deed punished. To some extent, such a 
phenomenon has hampered the reasonable development of various causes ${ }^{[3]}$. To solve this problem, a clear distinction should be made between reward and punishment. In ancient times, Han Feizi expressly put forward the idea that awards and punishments should be properly carried out. And his theories of management are a system of laws and methods. Laws refer to the legal system, which clarifies the government decrees and sticks to carry out awards and punishments properly; methods refer to the position-based accountability method and staffing method. Position-based accountability method means to" verify the reality according to the name", which is to investigate and verify the officials' actual achievements based on their positions; staffing method requires to" appoint officials based on their ability", which is to give officials the corresponding positions according to their abilities.

Good design managers should be good at motivating employees' loyalty for the cause and inspiring them to pull together to complete various objectives. This should not only make employees feel the delicate care, but also empower them to employ the authority and reach the effect of" tempering justice with mercy". In ancient times, rulers strongly advocated the leadership art of" tempering justice with mercy". To subordinates, rulers would offer them kindness in hopes of teaching them to be grateful. At the same time, they also strictly ordered the subordinates to follow their will. Otherwise, they would punish the subordinates, in hopes of protecting their own authority. As a manager, he should not only rain benefits on others, but also establish his authority. No benefit means any authority, and no authority achieves anything. Likewise, the material incentive and spiritual encouragement in the management filed are also quite similar. In Shanghai Yitian Industrial Design Company: the designers have no fixed project manager; as a matter of fact, depending on the project conditions, designers will act as project manager in turns; usually, the design team will keep one or two green-hands as reserves. Besides, the team has paid due respect to designers, regardless of the quality of their design works. At the same time, designers should keep energetic about their work. When a designer has worked at the same job for long and gets bored or loses passion, his job will be adjusted, or he will be shifted to other positions to activate his passion and energy, so that he can still have potential to tap and develop. In addition, the paid overtime system should be strictly observed ${ }^{[4]}$.

\subsection{Designers}

Designers are the soft talents of the company. They can summarize the information from various aspects; collect the conceptions of various roles and design out products that not only satisfy consumers' demand but also the company's psychological need. If the company's products are technical, it would be better to appoint a competent employee to take charge of the design work. If it can be expected that there will be much similar work in the long term and the product has the same characteristics, then it would be great to employ an industrial designer so that he can have a detailed understanding of the technical characteristics of product and thus improve the design quality.

(1) Freelance designers refer to those who are not employed by a certain company but are engaged in design independently. Since freelance designers are working independently, it's very important to manage their design work. For one thing, it should be guaranteed that the product made by each designer should be in line with the objective of the company. Designers should not design in their own way, as it may mess things up. For another thing, the continuity of design should be guaranteed and any replacement of designer won't lead to suspension of design. The design management should strike a certain balance between uniformity and creativity. If there are too many restrictions imposed on designers, it will strangle their creativity. However, if designers are allowed to design based on their own will, varieties of troubles may ensue and the design management will be out of control. Therefore, how to strike the balance has become the key of design management. 
As resident designers are employed by a certain company, they mainly do design work for the company.

(2) In most cases, resident designers are not working alone. A certain number of designers make up the design department of the company, or they join the product development department to engage in product design work. In order to coordinate the design work, appropriate arrangements have to be made in aspects of the organization structure and design management of designers. On the one hand, it should be guaranteed that the product design team and product development team can have a direct and effective communication in related aspects. On the other hand, the fundamental principle for evaluating the design work or the standard for evaluating the visual modeling should be established ${ }^{[5]}$.

\section{Design Team}

In the $21^{\text {st }}$ century, talent is the most precious element. However, a competitive and collaborative team is more precious. As technology becomes more and more complicated, design is no longer a personal pursuit, but has become a team activity. Teamwork is a concept that involves different aspects of company operation and industrial competition, and is also the organizational reason for the sustainable industrial innovation. It's not hard to find an excellent talent. However, to build an excellent team is not easy and needs good management. If the product development team lacks a harmonious atmosphere, then the management will be nothing and lack the practical significance.

Compared with artistic creation, industrial design is a comprehensive activity. The structure of the product developers is relatively complicated. Therefore, it requires the close collaboration between appearance designers and engineering technicians. As appearance designers and engineering technicians have different life experience and educational backgrounds, they also have different life habits, personalities, working modes, etc., which may result in their poor collaboration. For example, most appearance designers have artistic background. However, compared with engineers, they lack certain rational thinking, and they are relatively sensitive and sentimental. In the team, people tend to divide into factions, exclude and isolate some talents, which may result in the inharmonious atmosphere within the design team. Designers are watching out for others. They lack trust and have no sincere communication, which seriously impacts the work efficiency. This is a long-standing problem, which is hard to overcome ${ }^{[6]}$.

The harmonious collaboration within the industrial design team relies on the strengthening of management. Even though it's impossible to make a thorough change of the minds of appearance designers and engineering technicians, they should make some changes for their common goal. For example, a smooth communication mechanism among the team members should be strengthened so that all personnel involved in product development project can fully learn about their common goal and vision, and figure out their role, responsibility and task. Through management training, outdoor training and other methods, it can enhance the members' trust in each other. The design team members can learn to appreciate and encourage each other to contribute ideas and suggestions for their common goal, exchange ideas and resources, and express freely their feelings and opinions. In this way, a cooperation-based enterprise culture can be established, and employees can have a sense of belonging.

\section{Conclusion}

Based on an analysis of the designers and their effect on design process, this paper combined a concrete example of Design Company and elaborated the specific measures for design managers to better participate in the design activity and the importance of teamwork in industrial design. All in all, in terms of design management, there is nothing best, but something better. Most importantly, 
the talent management should conform to the actual condition and future development of the company.

\section{References}

[1] REN Gong-chang. Research the effect of industrial design to product maturity based on TRIZ[J], Machinery Design \& Manufacture,2009(3):264-265.

[2] LU Xi-mei. Product innovation design based on the theory of TRIZ and functional analysis[J], Machinery Design \& Manufacture,2010.(12):255-257.

[3] ZHANG Jian-yi. Innovation design of products based on TRIZ theory,Journal of machine design, 2009(2):35-37.

[4] FU Min. Reviews on integrated innovation methods for TRIZ-based product design[J], CHINESE JOURNAL OF CONSTRUCTION MACHINERY,2013(4):170-174.

[5] HOU lei. Optimal design for dry filter clip based on TRIZ theory[J], Machinery Design \& Manufacture,2011(7):240-242.

[6] CHEN Si-yuan. Innovative Design of New Wire-Saw Winding Equipment Based on TRIZ Theory[J], Machinery Design \& Manufacture,2013(1):4-6. 